\title{
Hydrodynamic behaviour and its effects on the treatment performance of panelled anaerobic baffle-cum filter reactor
}

\author{
R. Renuka ${ }^{1} \cdot$ S. Mariraj Mohan ${ }^{2} \cdot$ S. Amal Raj ${ }^{1}$
}

Received: 2 November 2014/Revised: 31 March 2015/Accepted: 25 April 2015/Published online: 27 May 2015

(C) Islamic Azad University (IAU) 2015

\begin{abstract}
The aim of this paper was to present the influence of hydraulic behaviour in the treatment of sewage (domestic wastewater) using panelled anaerobic baffle-cum filter reactor (PABFR). The PABFR has five compartments of equal size in which the first three compartments operate as anaerobic baffled reactor (ABR) followed by anaerobic filters (AF). The combined reactor has a great potential for its application due to its panelled structure and arrangement of baffles inside each compartment. Hydrodynamic behaviour of the reactor was determined by means of a pulse tracer test and by calculating the residence time distribution curves at different flow rates. At high flow rates [with hydraulic retention time $(\mathrm{HRT})<4 \mathrm{~h}$ ], the mixing pattern in ABR showed a completely mixed type with a maximum dead space of $14 \%$ and as the flow decreased (HRT of 8 and $12 \mathrm{~h}$ ), the ABR's mixing behaviour was intermediate between plug flow and completely mixed. In the case of $\mathrm{AF}$, as the flow increased, the dispersion was intermediate between completely mixed and plug flow, and as the flow rate decreased, the reactor became completely plug flow with the dead space ranging between 2.2 and $7.4 \%$. On the whole, PABFR treatment performance in terms of chemical oxygen demand removal was 90,89 and $64 \%$ for $12-, 8-$ and 4-h HRT, respectively, which clearly shows the correlation between mixing and reactor process performance.
\end{abstract}

R. Renuka

renuramakrishnan@gmail.com

1 Department of Civil Engineering, Centre for Environmental Studies, Anna University, Chennai 600025, Tamil Nadu, India

2 Department of Civil Engineering, Alagappa Chettiar College of Engineering and Technology, Karaikudi 630 004, Tamil Nadu, India
Thus, the outcome of this research in general highlights the importance of hydrodynamic behaviour for a better operation of the reactor.

Keywords Residence time distribution - Hydrodynamic behaviour . Panelled anaerobic baffled reactor cum filter reactor

\section{Introduction}

The application of anaerobic process on wastewater treatment has been studied intensively over the last few decades. The advantages of this type of digestion are that it does not require aeration, the construction costs are low, and large amounts of biogas is produced (Qi et al. 2013). Unstirred plug-flow (PF) anaerobic reactors often exhibit problems due to the accumulation of organic acids which decreases the $\mathrm{pH}$ level, ultimately resulting in poor reactor performance (Barber and Stuckey 1999). Studies on continuous stirred tank reactor (CSTR)-type anaerobic digestion have shown that the treatment performance is low due to high mixing frequency (Lindmark et al. 2014). Thus, optimum mixing is required to get a positive effect on anaerobic treatment performance.

The hydrodynamic behaviour in any biological reactor is of fundamental importance for the efficiency of wastewater treatment processes. The hydrodynamics and degree of mixing that occur within a biological reactor strongly influence the extent of contact between the substrate and bacteria, thus controlling mass transfer (Mansouri et al. 2012). Adequate mixing promotes transfer of a substrate to the micro-organism and also provides heat to maintain a uniform temperature, thus assuring the effective use of the 
entire reactor volume by preventing stratification (solid deposition and scum formation). The micro-organisms are sensitive to the intensity of mixing and may not survive excessive forceful mixing. Incomplete mixing jeopardizes the efficiency of treatment process, resulting in destitute effluent quality (Capela et al. 2009). Unfavourable hydraulic situations in the bioreactors may cause a lower process performance and thus higher residual concentrations in the treated effluent. Thus, mixing mode and intensity of mixing are the two important factors for good reactor configuration for efficient treatment.

The mixing of fluid in the reactor is broadly divided into two idealized models. One is continuously stirred tank model (CSTR) in which the reactor behaves as a homogenous mixing tank with infinite diffusion and backmixing, and the other one is PF reactor in which the flow passes in an orderly manner throughout the tank with no back-mixing and axial dispersion (Levenspiel 1999). A small deviation from the two ideal models can be caused by many factors such as recycling, fluid channelling by creation of dead zones, geometrical changes inside the reactor or by a combination of all these factors.

Tracer test is a proven method for determining the residence time distribution (RTD), defined as the timevarying distribution of a particle entering and leaving the system. In a tracer test, a known mass of a chemical substance (tracer) is added into the inlet stream of the reactor and the tracer concentration is detected and monitored at the outlet. RTD curves can then be generated from the data obtained from tracer tests, and by analysing the RTD curve, the hydraulic behaviour of the reactor can be characterized.

Many researchers (Liu et al. 2007; Grobicki and Stuckey 1992) studied the RTD response either in ABR or in AF using the pulse input tracer injection method in which lithium/sodium/dye (rhodamine B) was used as the inert tracer substance to inject and observe the fate of the material in the outlet of the effluent at various hydraulic retention times (HRTs). The data obtained from the RTD curve were incorporated into the "dispersion model" and "tank-in-series model" as given in (Levenspiel 1999). Thus, the model calculates the dispersion (degree of mixing), dead space (unused volume), short circuiting and hydraulic efficiency.

Grobicki and Stuckey (1992) and Gopala Krishna et al. (2008) studied the hydrodynamics of the eight-chambered ABR in which they found out that the pattern was intermediate between CSTR and PF, but as the HRT or number of compartments in ABR increased, the reactor behaved like a PF reactor. The studies of Sarathai et al. (2010) revealed the hydraulic characteristics of ABR under unsteady flow conditions, that is, twofold-fourfold higher than the average flow condition, the ABR was found to be "intermediate" between PF and completely mixed.
However, the mixing pattern of ABR tends to become a completely mixed reactor when the peak flow factor was increased to more than six times the normal flow. The dead space observed was $26 \%$ which was relatively lower than other high-rate anaerobic systems.

In the present work, a tracer analysis is carried out on PABFR treating domestic wastewater using rhodamine B as tracer, thereby investigating the influence of hydrodynamic behaviour on the working performance of the reactor and thus highlighting the role of reactor configuration. The superior design requires in-depth understanding of the hydrodynamics (flow pattern) within the system, by considering the geometry (number of chambers, baffle positioning, number of baffles, filter media characteristics) of the reactor for better performance. To obtain accurate knowledge of mixing behaviour in the PABFR, the RTD study was conducted to assess the extent of dispersion (back-mixing) using axial dispersion in plug-flow model and tank-in-series model, volume of dead space, short circuiting and hydraulic efficiency of the reactor. Thus, appropriate hydraulic design not only improves the pollutant removal efficiency, but also reduces costs and achieves optimal treatment and engineering benefits. Thus, the RTD studies highlight the problems associated with performance efficiency of the treatment system due to mixing, based on HRT.

The experimental set-up of PABFR was kept at sewage treatment plant (STP), Anna University, Chennai, Tamil $\mathrm{Nadu}$, India. The studies were carried out for the period (March 2012-November 2014).

\section{Materials and methods}

\section{Experimental set-up of panelled anaerobic baffle- cum filter reactor (PABFR)}

The schematic diagram of the experimental set-up of PABFR is shown in Fig. 1. The reactor was made of

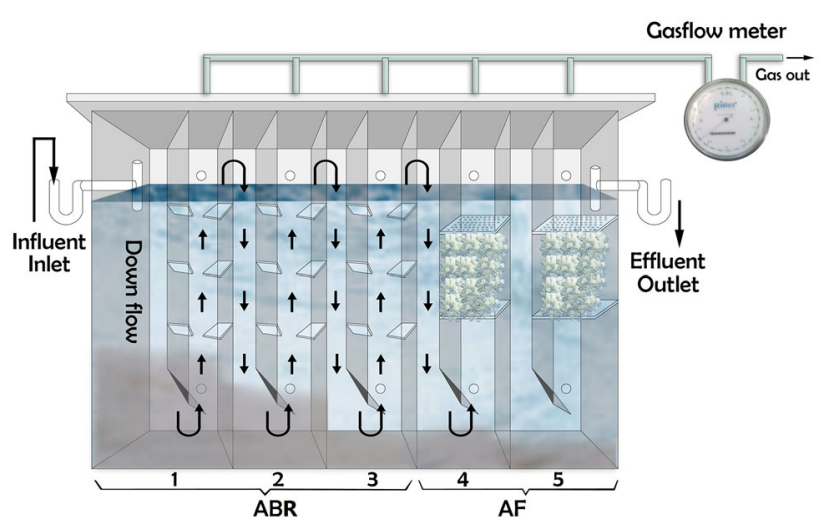

Fig. 1 Schematic of PABFR 
transparent plexiglass of $6 \mathrm{~mm}$ thickness. The configuration parameters of PABFR were: length $60 \mathrm{~cm}$, height $48 \mathrm{~cm}$ and breadth $40 \mathrm{~cm}$. It consisted of five chambers which are in turn divided into three up-flow anaerobic baffled chambers (ABR1, ABR2 and ABR3) followed by two anaerobic filter chambers (AF4 and AF5) of equal size, shape and volume, connected in series. To collect the biogas produced, five separate gas manifolds were provided and the biogas was finally let into the biogas flow meter (Ritter milligas flow meter drum-type, Germany). The liquid and sludge samples were collected from the ports placed at the top and bottom of all the five chambers in the reactor. The individual chamber was again divided into two by hanging baffle, that is, down- and up-comer. The ratio between the up-comer and down-comer was maintained at $1: 3$, and the bottom portion of the baffle was inclined at $45^{\circ}$, and three more baffles were also placed on either side of the inner wall. The anaerobic filter (AF) chambers were filled with plastic pall ring media. The description of the plastic media is given in Table 1. The total volume of the panelled anaerobic baffled cum filter reactor was $115 \mathrm{~L}$ with a net working volume of $100 \mathrm{~L}$. The volume of the individual set of chambers (ABR1, ABR2, ABR3, AF4 and AF5) was $20 \mathrm{~L}$ before the AF was filled with media. The net volumes of the down-comer and the up-comer were 5 and $15 \mathrm{~L}$, respectively.

\section{Analysis}

The reactor was monitored daily for $\mathrm{pH}$, temperature and biogas. Chemical oxygen demand (COD) and total suspended solids (TSS) were measured twice a week. Liquid samples were collected from the effluent port located on the front side, at the top of the reactor. Sampling is done from each compartment, starting from the last compartment towards the first to prevent air intrusion and to maintain anaerobic condition. All parameters were determined according to standard methods (APHA 1998).

\section{Tracer experimental procedure}

A unique technique used for studying the flow pattern in a reactor is the analysis of tracer-response studies. Tracer analysis is based on many factors such as up-flow velocity of the fluid inside the reactor, biogas formation and its mixing, biomass accumulation. The hydraulic characteristics of the PABFR were determined using RTD studies. The RTD study was conducted separately for anaerobic baffled reactor units and AF units using the pulse input tracer method. The pulse input method is more advantageous than the step input method because only a small quantity of highly concentrated tracer chemical was injected into the inlet and response was observed at the outlet; thus, the RTD curve was developed. In the case of step input method, the tracer chemical is injected at a constant rate until the tracer concentration reaches steady state; thus for economical reasons, the pulse injection method was preferred. Jimenez et al. (1988) suggested rhodamine $\mathrm{B}$ as one of the inert tracer materials, and (Mansouri et al. 2012) used rhodamine B as tracer material to study the hydraulic characteristics of anaerobic rotating biological contractor for wastewater treatment because this substance is not absorbed or does not react with the exposed surface of the reactor; moreover, it can be detected at very low concentrations using UV-visible spectrophotometer. Pritchard and Carpenter (1960) used rhodamine B for measuring the turbulent estuarine and in inshore waters because the fluorescence of rhodamine B is not affected by $\mathrm{pH}$ of the medium over the range 4-10.3 units and adsorption of rhodamine B in suspended particles and living materials in Chesapeake bay water was not significant ( $0.40 \mathrm{ppb}$ of rhodamine $\mathrm{B}$ in a sample which contained a large algal population showed no decrease in fluorescence over 4 days). Wolkersdorfer (2011) used rhodamine B and uranine (Na-fluorescein) for tracer study of mine water in settling pond and constructed wetland. The absorption spectra of rhodamine B were obtained in the range of $400-630 \mathrm{~nm}$. The maximum absorption appeared at room
Table 1 Characteristics of filter media

\begin{tabular}{ll}
\hline Description & Values \\
\hline Effective specific surface area of media $\left(\mathrm{m}^{2} / \mathrm{m}^{3}\right)$ & 400 \\
Height $(\mathrm{mm})$ & 16 \\
Diameter of media $(\mathrm{mm})$ & 22 \\
Type of media $(-)$ & Fluidized biomedia \\
Structure $(-)$ & Cylindrical with external fins \\
Specific gravity $(-)$ & $0.90-0.95$ \\
Maximum continuous operation temperature $\left({ }^{\circ} \mathrm{C}\right)$ & 80 \\
Voidage $(\%)$ & $>95$ \\
\hline
\end{tabular}


temperature with UV-visible spectrophotometer at $554 \mathrm{~nm}$ (Mansouri et al. 2012). This maximum absorption was used throughout the experiments.

Tracer test is one of the tools used to evaluate by collectively examining the mixing pattern, which is dispersion, extent of short circuiting, dead space (stagnant or unoccupied space) and hydraulic efficiency of the reactor based on the dispersion model. The effluent samples were taken at regular time intervals from the time of pulse tracer injection to 2.5 times of the normalized HRT.

\section{Theoretical interpretation}

The normalized RTD curve is determined as a function of normalized time Eq. 1 against normalized tracer concentration Eq. 2 as explained by Metcalf and Eddy (2003)

Normalized time $(\theta)=\frac{\operatorname{time}(t)}{\operatorname{HRT}(t)} \quad$ or $\quad \theta=T_{\mathrm{i} / \tau}$

where $\theta$ is the normalized time is (dimensionless), $T_{\mathrm{i}}$ is the sampling time and $\tau$ is the ideal or nominal HRT

$$
\begin{aligned}
& \text { Normal concentration } C^{*}=\frac{\text { Concentration at time }(T)}{\text { Initial concentration }} \\
& \qquad C^{*}=\frac{C_{T}}{C_{\mathrm{i}}}
\end{aligned}
$$

where $C^{*}$ is the normalized concentration (dimensionless), $C_{T}$ is the concentration of tracer at time $T$ and $C_{\mathrm{i}}$ is the initial tracer concentration at the time of injection.

The normalized curve is known as RTD curve, and when a pulse addition of tracer is used, the area under the normalized curve is known as $E$ curve (exit age curve), that is the time take for the fluid stream to come out of the reactor. The most important characteristic of the $E$ curve is that the area under the curve is equal to 1 as defined in Eq. 3

$\int_{0}^{\infty} E(t) \mathrm{d} t=1$

where $E(t)$ is the RTD function. The $E(t)$ value is related to the $C(t)$ value as shown in Eq. 4, which was used to calculate $E(t)$, the mean residence time $\bar{t}$, and $\sigma_{t}^{2}$ variance of RTD studies.

$$
\begin{aligned}
E(t) & =\frac{C(t)}{\int_{0}^{\infty} C(t) \mathrm{d} t}, \\
\bar{t} & =\int_{0}^{\infty} t E(t) \mathrm{d} t / \int_{0}^{\infty} E(t) \mathrm{d} t, \quad \sigma_{t}^{2}=\int_{0}^{\infty} t^{2} E(t) \mathrm{d} t-(\bar{t})^{2}
\end{aligned}
$$

The hydrodynamics of any anaerobic reactor is described by non-ideal flow models, because the curve produced by the tracer test deviates from the ideal flow model, depending on the extent and type of mixing found in the reactor. Modelling of panelled anaerobic baffled cum filter reactor was carried out using the following nonideal reactor models as described in Eqs. 7 and 9, respectively.

\section{Axial dispersion in plug-flow model (minimum back- mixing)}

In the case of relatively low back-mixing, the axial dispersion model was applied (Ji et al. 2012). Assume that back-mixing occurs only in the axial direction which is represented by the axial dispersion coefficient; the mixing in the radial direction can be neglected further. It is assumed that the fluid possesses a constant velocity and constant substrate concentration across the bed diameter. By applying Fick's law in the axial direction considering the reactor under steady state, the axial dispersion model can be easily established in Eq. 5 as explained in (Ren et al. 2008)

$\frac{\partial C(t)}{\partial t}=D \frac{\left(\frac{\partial C(t)}{\partial t}\right)}{\partial t}-u \frac{\partial C(t)}{\partial l}$

where $D / u L$ represents the axial dispersion coefficient, $\mathrm{m}^{2} /$ $\min , l$ is the axial distance of the reactor $(\mathrm{m})$ and $u$ the average fluid velocity $(\mathrm{m} / \mathrm{min})$. The dimensionless concentration $C^{*}=C_{T} / C_{\mathrm{i}}\left(C_{T}\right.$ is the tracer concentration at time $T, C_{\mathrm{i}}$ the initial tracer concentration), dimensionless time $\theta=T_{\mathrm{i}} / \tau$ and length $\mathrm{Z}=l / L$ ( $L$ the length of the reactor) were used and Eq. 5 becomes:

$\frac{\partial C^{*}(\theta)}{\partial \theta}=\left(\frac{D}{u L}\right) \frac{\partial\left(\frac{\partial C^{*}(\theta)}{\partial Z}\right)}{\partial Z}-u \frac{\partial C^{*}(\theta)}{\partial Z}$

where $D / u L$ is the dispersion number (dimensionless), which characterizes the degree of back-mixing in the direction of flow. The larger the number, the stronger the back-mixing. Solving the partial differential Eq. 6 and using inter-relationship prescribed in various literature such as Fogler (2006), Chen et al. (2010), Ji et al. (2012), we obtain Eq. 7

$\sigma_{\theta}^{2}=\frac{2}{(u L / D)}-\frac{2}{(u L / D)^{2}}\left(1-\mathrm{e}^{-u L / D}\right)$

where $\sigma_{\theta}^{2}$ is the dimensionless variance of the RTD, $\sigma_{\theta}^{2}=$ $\frac{\sigma_{t}^{2}}{\bar{t}^{2}}$. Thus, $D / u L$ could be computed using Eqs. (4) and (7). If $D / u L \rightarrow 0$, the reactor approximated to the ideal PF reactor, and if $D / u L \rightarrow 1$, the reactor approximated to the ideal continuous-flow stirred tank reactor. In the case of nonideal flow, the dispersion will be in the range $0<D /$ $u L<1$. 


\section{Tank-in-series model-TIS (strong back-mixing)}

In the case of relatively strong back-mixing, the TIS model was applied as suggested by Grobicki and Stuckey (1992). In the TIS model, the variation rate of tracer concentration in an infinitesimal volume is expressed as Eq. 8:

$C(t)=\frac{C o}{(N-1) !}(t / \tau)^{N-1} \mathrm{e}^{-t / \tau}$

where $\tau$ is the HRT for each reactor and $N$ is the number of TIS. Then, $\sigma_{\theta}^{2}$ in Eq. 8 is:

$\sigma_{\theta}^{2}=\int_{0}^{\infty} \frac{N^{N} \theta^{N+1} \mathrm{e}^{-N \theta}}{(N-1) !} \mathrm{d} \theta-1=\frac{1}{N}$

Rearranging Eq. 9, we obtain:

$N=\frac{1}{\sigma_{\theta}^{2}}$

Thus $N$, the main parameter of the TIS model, could be calculated by Eq. 10. The TIS model simulated the actual CSTR reactor with the same volume in series. If $N \rightarrow 1$, the reactor approximated to CSTR, and if $N \rightarrow \infty$, the reactor approximated to PFR.

Dead space of the reactor $\left(V_{\mathrm{d}}, \%\right)$ could be calculated following Eq. 11 as explained by Sarathai et al. (2010):

$V_{\mathrm{d}}(\%)=(1-\bar{t} / \tau) \times 100$

Metcalf and Eddy (2003) explained short circuiting as a complicated phenomenon that influences reactor performance. It is considered as one of the greatest hindrances to the success of the reactor (Tsai et al. 2012). Short circuiting $(\Psi)$ is the ratio between the first appearances of the tracer in the outlet of the effluent $\left(\tau_{\mathrm{k}}\right)$ and the actual HRT $(\tau)$ or nominal HRT as shown in Eq. 12. A ratio of $<0.3$ reveals that the flow has a distinct short-circuiting effect (Tembhurkar and Mhaisalkar 2006).

$\Psi=\frac{\tau_{\mathrm{k}}}{\tau}$

The hydraulic efficiency represents the ability of the system to distribute its flow uniformly throughout its volume, maximizing the contact time of pollutant in the system and optimizing the ability to break down the pollutants. The hydraulic efficiency of the reactor is expressed as shown in Eq. 14 which reflects two features as described by Persson et al. (1999) and Holland et al. (2004):

(1) The distribution of inflow across the reactor and (2) the mixing of fluid inside the reactor. Hydraulic efficiency proposed by Thackston et al. (1987) is given in Eq. 13

$\lambda_{\mathrm{t}}=\bar{t} / \theta_{\mathrm{s}}$
Hydraulic efficiency proposed by Thackston et al. (1987) was enhanced by the hydraulic efficiency proposed by Persson et al. (1999) as per Eq. 14.

$\lambda_{\mathrm{p}}=\lambda_{\mathrm{t}}(1-1 / N)$

where $\bar{t}$ is the mean residence time, equivalent to RTD centroid, $\theta_{\mathrm{s}}$ is the theoretical residence time and $N$ is the number of tanks in series. $\lambda_{\mathrm{t}}$, the hydraulic efficiency proposed by Thackston et al. (1987), and $\lambda_{\mathrm{p}}$, the hydraulic efficiency proposed by Persson et al. (1999) were used in this work. The value range of hydraulic efficiency varies from 0 to 1 , and it is classified into three groups: (1) good hydraulic efficiency with $\lambda_{\mathrm{p}}>0.75$, (2) satisfactory hydraulic efficiency $0.75<\lambda_{\mathrm{p}} \geq 0.50$ and (3) poor hydraulic efficiency $\lambda_{\mathrm{p}}<0.50$.

\section{Tracer recovery}

The total mass of recovered tracer at the outlet of PABFR at the end of the tracer study was defined by Bodin et al. (2012) as shown in Eq. (15)

$M_{\text {out }}=\int_{0}^{\infty} Q_{\text {out }}(t) C_{\text {out }}(t) \mathrm{d} t$

where $M_{\text {out }}$ is total mass recovered tracer at outlet $(\mathrm{mg})$, $Q_{\text {out }}(t)$ is outflow rate of effluent at time $t\left(\mathrm{~m}^{3} / \mathrm{h}\right), C_{\text {out }}(t)$ is outlet tracer concentration at time $(\mathrm{mg} / \mathrm{L}), t$ is time of sampling (h) and $\mathrm{d} t$ is difference in time between sampling (h).

The relative tracer mass recovery is given (Eq. 16)

Mass recovery $(\%)=\left(M_{\text {out }} / M_{\text {added }}\right) \times 100$

\section{Results and discussion}

\section{HRT distribution of PABFR}

The hydraulic characteristics of the reactor were studied using the pulse input tracer test. RTD studies were carried out to examine the mixing behaviour of PABFR. The tracer test was performed in three runs for all HRTs, and the mean value obtained was considered in this study. The normalized concentration of rhodamine B in the outlet was plotted against normalized time. Figure $2 \mathrm{a}-\mathrm{c}$ shows the RTD curve for HRT 12, 8 and $4 \mathrm{~h}$ of ABR chamber, and Fig. 3a-c shows the RTD curve at 12,8 and $4 \mathrm{~h}$ for AF chamber. Tracer recovery efficiency was calculated using Eqs. 15 and 16. In Table 2, it is observed that recovery efficiency of the tracer varied between 74 and $85 \%$ for ABR and $72-78 \%$ in case of AF. 
Fig. 2 a-c RTD graph of anaerobic baffled reactor at 12 , 8 and $4 \mathrm{~h}$

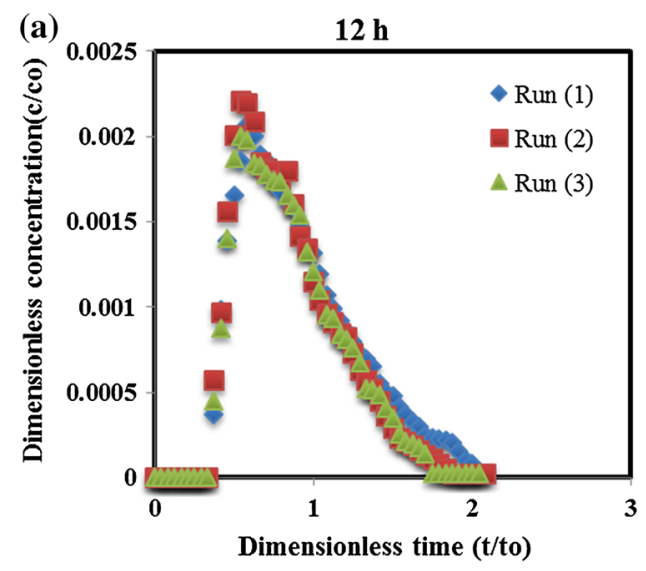

(b)
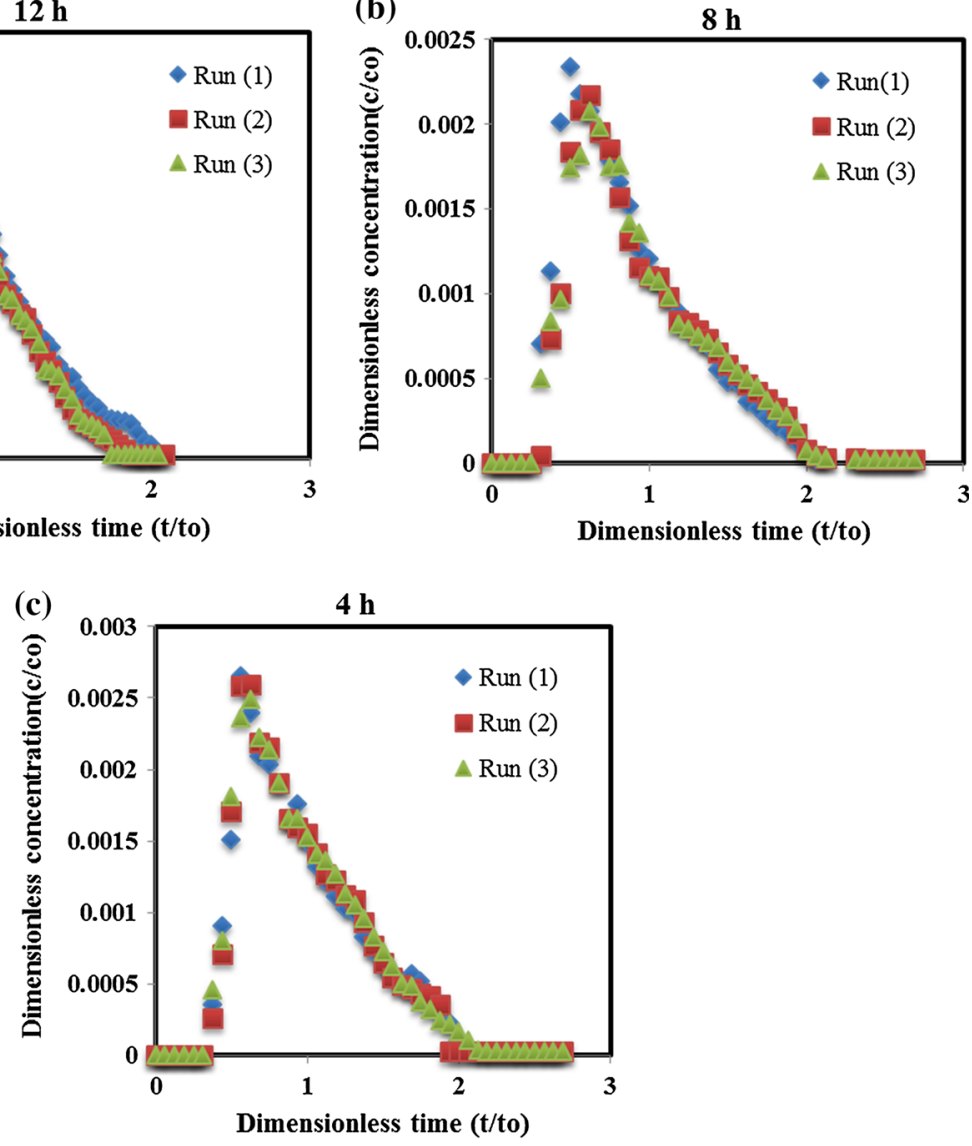

Fig. 3 a-c RTD graph of anaerobic filter chamber at 12,8 and $4 \mathrm{~h}$ (b)
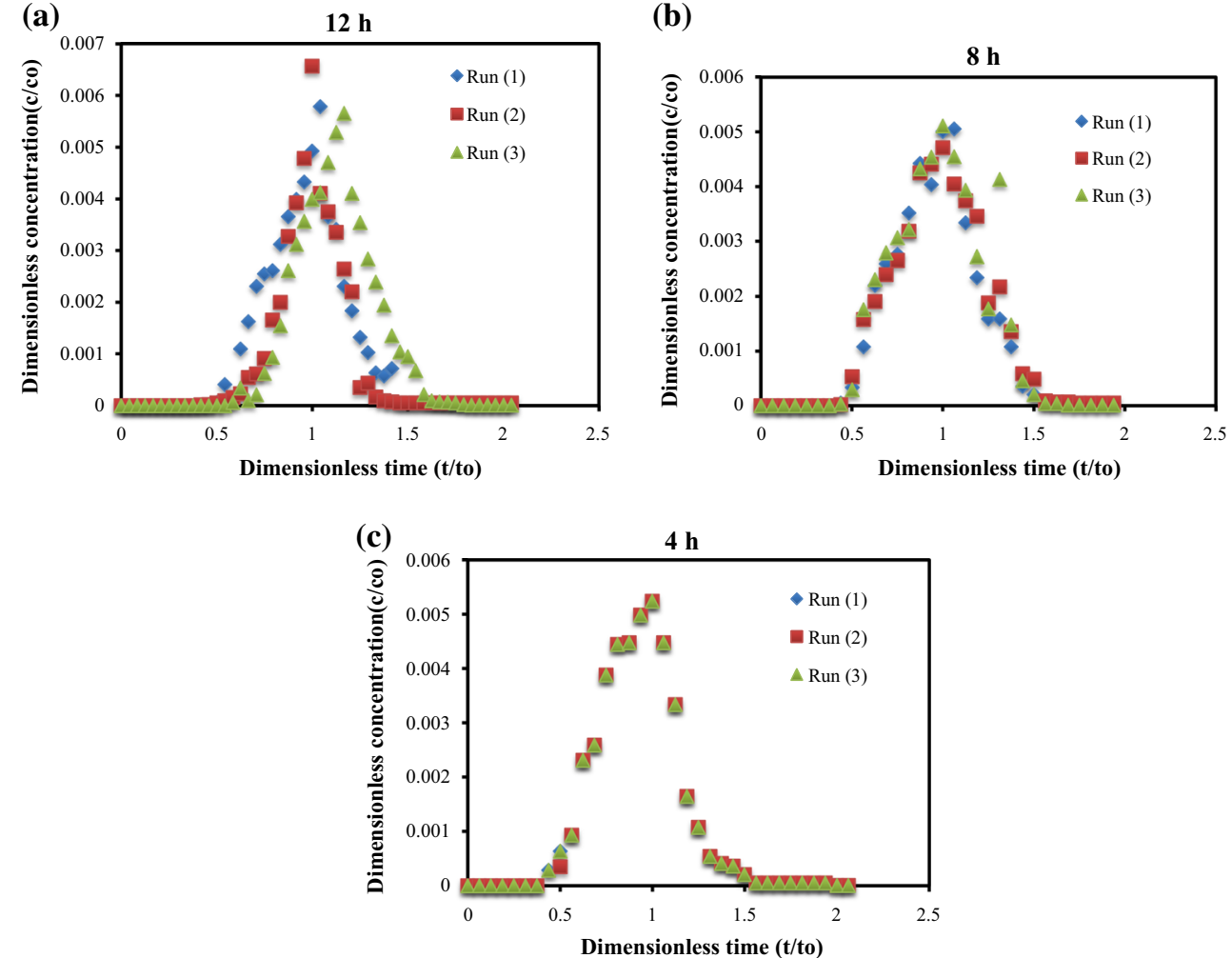
Table 2 Hydraulic characteristics of PABFR

\begin{tabular}{lllllll}
\hline Parameters & \multicolumn{3}{l}{ Anaerobic baffled chamber } & \multicolumn{3}{l}{ Anaerobic filter chamber } \\
\hline Hydraulic retention time $(\mathrm{HRT})(\mathrm{h})$ & 12 & 8 & 4 & 12 & 8 & 4 \\
Mean residence time $(\mathrm{MRT})(\mathrm{h})$ & 10.5 & 6.9 & 3.5 & 11.7 & 7.8 & 3.7 \\
Volume of dead space $\left(V_{\mathrm{d}}\right)(\%)$ & 12.5 & 13.8 & 14.2 & 2.2 & 2.7 & 7.4 \\
Short circuiting $(\Psi)(-)$ & 0.33 & 0.31 & 0.37 & 0.50 & 0.44 & 0.44 \\
Dispersion number $(D / \mu L)(-)$ & 0.088 & 0.100 & 0.227 & 0.013 & 0.018 & 0.026 \\
Dispersion in plug flow $\left(\sigma_{\theta}^{2}\right)(-)$ & 0.176 & 0.200 & 0.454 & 0.025 & 0.036 & 0.052 \\
No. of tank in series $(N)(-)$ & 5.68 & 5.00 & 2.20 & 39.68 & 28.09 & 19.23 \\
Volumetric efficiency $\left(\lambda_{\mathrm{p}}\right)(-)$ & 0.72 & 0.69 & 0.47 & 0.88 & 0.87 & 0.81 \\
Tracer recovery $(\%)$ & 79 & 85 & 74 & 78 & 76 & 72
\end{tabular}

By comparing the RTD curves obtained for ABR and $\mathrm{AF}$, it was found that the peak concentration of tracer left the reactor before $t / t_{0}$ is equal to 1 in the case of $\mathrm{ABR}$, and $t / t_{0}$ is closer to 1 in the case of AF. The curves were analysed for mean residence time and variance.

Once the tracer is introduced into ABR chamber, the liquid flows in a pattern or follows a path with meagre interference caused by biomass and addition of baffles; hence, $C / C_{0}$ peak value is similar. In case of $\mathrm{AF}$ chamber, the packed might have influenced the flow pattern; hence in each run, different peak values are observed. Furthermore, the time gap between two sampling was short in case of anaerobic baffled chamber, but in case of $\mathrm{AF}$, the time gap maintained between two samples was little longer. Thus, the difference was observed.

In case of Fig. 3a-c, the 12-h HRT has small peak of normalized concentration corresponding to the lowest calculated value of dead space in AF. This corresponds to the lowest organic loading rate, because at 12-h HRT, tracer diffused into effluent slowly than at 8- and 4-h HRT. Furthermore, more tail area at 12-h HRT corresponds to lower calculated dead space in AF. Thus, as dead space increased, tail area in AF reduced. But in ABR, tail area increased as dead space increased. This clearly indicates the change in flow pattern in ABR and AF. This result was further verified by finding that dispersion in ABR lies between CSTR and plug flow, whereas the pattern follows plug flow in AF.

As far as Table 2 is concerned, recovery efficiency increased as HRT increased in AF. In AF, highest dead space of $7.4 \%$ was obtained at 4-h HRT. If dead space is higher, there is a possibility of portion of tracer stayed over there, paving the way for lower tracer recovery efficiency. At 8and 12-h HRT, dead space is decreased in AF, which leads to increase in recovery efficiency. But in ABR, based on $D /$ $u L$ value, it was inferred that the ABR portion of the reactor lies between mixed and plug flow, which gave rise to better condition for efficient treatment. In ABR, irrespective of dead space obtained, better performance was obtained at 8-h HRT on a par with 12-h HRT. This fact was further verified as the reactor was subjected to long-term run (529 days) under different HRTs. To substantiate above findings, better recovery efficiency was obtained at 8-h HRT of PABFR.

\section{Mixing patterns and hydraulic model}

Mixing patterns are associated with the variance obtained from the experimental data plotted in the $C$-curve. Table 2 shows the hydraulic traits of ABR and AF separately. The experimentally derived information was fitted into the axial dispersion in plug-flow (DPF) and TIS model. In the axial dispersion model as given in Eq. 7, the dispersion numbers $(D / u L)$ were $0.088,0.100$ and 0.277 for HRTs 12,8 and $4 \mathrm{~h}$ in ABR and 0.013, 0.018 and 0.026 for HRT 12, 8 and $4 \mathrm{~h}$ in AF, respectively. Tomlinson and Chambers (1979) elucidate that, when the reactor approximates to single CSTR, it has a large dispersion number $(D / u L \geq 0.2)$ implying a high degree of longitudinal mixing, which was noticed in ABR with a less retention time of $4 \mathrm{~h}$. The axial dispersion (backmixing) becomes relatively weak in the retention time of 8 and $12 \mathrm{~h}$ with dispersion numbers in the range $0.02 \leq D /$ $u L \leq 0.2$, showing that the flow pattern is intermediate between completely mixed and PF (moderate back-mixing) which is an ideal condition for an efficient treatment performance. In the case of $\mathrm{AF}$, the dispersion number was $0.02 \leq D / u L \leq 0.2$, with a low retention time of $4 \mathrm{~h}$, implying moderate back-mixing, and in higher retention times of 8 and $12 \mathrm{~h}$, the dispersion number $D / u L \leq 0.02$; thus, the flow pattern tends to be completely PF.

The TIS model estimates the number of equal-sized stirred tanks $(N)$, and $N$ can be obtained from the reciprocal of the variance from the $C$-curve. The volume of each stirred tank is the total reactor volume divided by $N$ (Grobicki and Stuckey 1992). Based on the TIS model Eq. 8, the series numbers $N$ were calculated as 5.68, 5.00 and 2.20 for 12-, 8- and 4-h retention times in ABR, and in the case of AF, the series numbers were 39.6, 28.09 and 19.23 for 12-, 8- and 4-h retention times, respectively. From the results obtained, it is clear that at higher retention times, the 
flow pattern approaches PF $(N \rightarrow \infty)$, and at lower retention times, the flow pattern tends to approach completely mixed flow $(N \rightarrow 1)$. Thus, back-mixing predicted by the TIS model showed the same tendency as predicted by the axial dispersion model.

According to Chen et al. (2010), back-mixing is one of the important parameters which decide the performance of the reactor. The conversion rate of pollutants in the PF reactor (no back-mixing) is higher than in the continuously stirred tank reactor (maximum back-mixing), but the organic loading distribution in PFR is uneven within the same compartment, which affects the performance of the anaerobic reactor (Smith et al. 1996). Thus, it is inferred that moderate back-mixing (axial dispersion) is necessary for making contact between the substrate and biomass (micro-organism) within the reactor to maintain equilibrium between the acid produced from the volatile fatty acid at the bottom of the reactor and alkali produced by the formation of methane in the top of the reactor. Moderate mixing inside the reactor enhances nutrient conversion and alkalinity production.

Qi et al. (2013) studied the hydraulic character simulation in ABR (self-agitated) using computational fluid dynamics (CFD) and found that the first and third chambers of the reactor behave very much like CSTR since the gas storage and release cause a change in the liquid level. The diffusion in the fourth chamber is much weaker, and the flow characteristic tends to PF, due to the decrease in organic loading and gas production. Kobayashi and Li (2011) studied the self-agitated anaerobic reactor and found that alkalinity and $\mathrm{pH}$ value were distributed equally in the first three compartments due to CSTR flow condition; slight rise in the $\mathrm{pH}$ and alkalinity was noticed in the fourth chamber which behaves like PF type. Ji et al. (2014) investigated the hydrodynamic behaviour of staged up-flow anaerobic ammonium oxidation (ANAMMOX) sludge bed (SUASB) reactor and found that the reactor behaviour was in between PF and CSTR.

\section{Short circuiting and dead space}

The actual HRT should be equal to the theoretical HRT in the case of ideal reactors, but invariably in all practical reactors, the actual HRT always deviates from the theoretical HRT because of many factors such as short circuiting and stagnant zones ( $\mathrm{Ji}$ et al. 2012). Short circuiting is a complicated phenomenon in reactors which hinders the successful design by producing a dead zone (Tsai et al. 2012). According to Metcalf and Eddy (2003), the consequence of inadequate mixing, poor design, density currents and channelling effect leads to short circuiting and dead space. The index of short circuiting Eq. 12 was above 0.3 for all the observed residence times
(12, 8 and $4 \mathrm{~h}$ ) both in ABR and AF, which signifies that there is no distinct short circuiting in the designed reactor. The total dead space (TDS) was divided into two categories, namely biological dead space (BDS) and hydraulic dead space (HDS). The BDS is the volume occupied by the biomass and interference caused by biomass particles during the flow, and the HDS is the unused volume occupied beneath the weirs and corners, and also it is the function of flow rate and number of compartments inside the reactor. TDS is the function of the product of the mean of the curve and the area under the curve between $\theta=0$ and $\theta=2$ (that is, the total area minus the tail) (Grobicki and Stuckey 1992). In ABR, the TDS increased from 12.5 to $14.2 \%$, as the HRT decreased from 12 to $4 \mathrm{~h}$; this may be because of the channelling effect due to increased flow rate. In the present study, dead space increased as HRT decreased. At the same time, as the HRT decreased, the OLR of the reactor increased, and this may result in biogas production equivalent to biogas production at higher HRT, if COD removal efficiency is constant. This can be seen in Table 3. The COD removal efficiency for 8-h HRT is $89 \%$ which is closer to $90 \%$ COD reduction at 12-h HRT. In these two HRTs (12 and $8 \mathrm{~h}$ ), almost the same amount of biogas production was experienced. Because of decreasing HRT (4 h), more mixing in the reactor occurs, thus creating less BDS and counter-balancing the increase in HDS in the reactor. Sarathai et al. (2010) compared the dead space results of anaerobic baffled reactor with and without addition of sludge and observed no visible significant difference in the dead space percentage in both the cases. In general, when the feed wastewater is of low strength (COD $<500 \mathrm{mg} / \mathrm{L}$ ), the HDS dominates, and when the feed wastewater is of high strength (more than $3000 \mathrm{mg} / \mathrm{L}$ ), BDS dominates. In the present study, when HRT is high, the OLR is low; hence, the dead space is caused only by HDS, and when HRT is low, the OLR is high that created the BDS. Therefore, HDS and BDS counter-balance each other. In the case of AF, the dead space increased from 2.2 to $7.4 \%$ for HRT $12-4 \mathrm{~h}$; this is because of the packing media that are loosely filled inside the reactor, which helped in mixing of the tracer.

\section{Hydraulic efficiency}

Hydraulic efficiency Eq. 14 is associated with the effective volume and flow pattern; hence on the one hand, it is related to the working performance of the anaerobic reactor, and on the other hand, it is influenced by hydraulic characteristics (Terashima et al. 2009). Persson et al. (1999) categorized the hydraulic efficiency into three groups: good $\left(\lambda_{\mathrm{p}}>0.75\right)$, satisfactory $\left(0.75 \leq \lambda_{\mathrm{p}} \geq 0.50\right)$ and poor $\left(\lambda_{\mathrm{p}}<0.50\right)$. The hydraulic efficiency of ABR at 12,8 and 
Table 3 Summary of treatment performance of PABFR

\begin{tabular}{lllll}
\hline Parameter & Influent & \multicolumn{4}{l}{ Effluent of PABFR } & \\
\cline { 3 - 5 } & & HRT 12 h & HRT 8 h & HRT 4 h \\
\hline OLR $\left(\mathrm{kg} \mathrm{COD} / \mathrm{m}^{3} /\right.$ day) & - & $1.26 \pm 0.24$ & $1.97 \pm 0.27$ & $3.43 \pm 0.60$ \\
COD $(\mathrm{mg} / \mathrm{L})$ & $650 \pm 107$ & $66.4 \pm 9.73$ & $71.2 \pm 5.75$ & $236.2 \pm 8.07$ \\
COD removal $(\%)$ & - & 90 & 89 & 64 \\
Biogas yield $\left(\mathrm{m}^{3} / \mathrm{kg}\right.$ COD destroyed) & - & $0.33 \pm 0.02$ & $0.32 \pm 0.02$ & $0.22 \pm 0.01$ \\
SS (mg/L) & $408.3 \pm 87.0$ & $20 \pm 3.95$ & $21 \pm 1.53$ & $66 \pm 2.6$ \\
SS removal $(\%)$ & - & 95.1 & 94.8 & 83 \\
\hline
\end{tabular}

4 h was 0.72, 0.69 and 0.47, respectively, and for AF at 12, 8 and $4 \mathrm{~h}$, it was $0.88,0.87$ and 0.819 , respectively. The hydraulic efficiency of ABR was satisfactory at 12- and 8-h HRT and worsens when the retention time was decreased to $4 \mathrm{~h}$; thus, it is confirmed that the mixing pattern has a serious effect on the hydraulic efficiency. In the case of AF, the hydraulic efficiency falls under the category of good in all the retention times. Thus, the hydraulic efficiency represents the ability of the system to distribute its flow uniformly throughout its volume, maximizing the contact time of pollutant in the system and optimizing the ability to break down the pollutants.

\section{Performance of treatment process}

PABFR performance was consistent throughout the experiment after reaching steady-state operation. The HRT was gradually changed by increasing the flow rate; after every adjustment in the HRT, fluctuation was observed in the effluent quality, which was gradually decreased after stabilization. Hydrodynamic behaviour along with inoculums, biomass, temperature, $\mathrm{pH}$, etc. is required for the good reactor treatment performance. Appropriate mixing inside anaerobic reactor is necessary, to transfer the substrate and heat to the micro-organism and maintain uniform temperature and other environmental factors favourable. The mixing promotes effective use of entire reactor volume and prevents stratification (solid deposition and scum formation). Thus, it can be interpreted that proper mixing along with active biomass is vital for stable treatment performance. During the total period of PABFR operation (529 days), the performance evaluation was carried out at seven different HRTs such as 40, 24, 12, 8, 6, 4 and $2 \mathrm{~h}$. In this study, only three HRTs (12, 8 and 4 h) were taken in order to compare and correlate with the hydrodynamic behaviour of the reactor. It was observed that the overall performance efficiency in terms of reduction in SS, COD and specific biogas yield was decreased as the HRT was lowered to $4 \mathrm{~h}$. The actual domestic sewage was taken for the experiment; hence, the fluctuation in the influent concentration was observed throughout the reactor operation.
The treatment performance of PABFR was carried out by a combination of anaerobic baffled reactor and anaerobic filter; thus, in Fig. 4, the COD concentration at the outlet of $\mathrm{ABR}$ and $\mathrm{AF}$ is shown along with the removal efficiency at different HRTs.

Many researchers (Bodkhe 2009; Feng et al. 2008) have observed a linear relationship between SS, COD removal and HRT, i.e. as the HRT decreased, the removal efficiency COD and SS was also decreased. In this study, to identify any significant difference between COD and suspended solids removal efficiencies $(\%), t$ test was performed. The $t$ test was designed to test whether the means of two groups are statically different from each other or not. The $t$ test was conducted at $5 \%$ level of significance. From the observed values, the calculated $t$ value of 1.06 was less than the critical value of 2.77 which was taken from the $t$ table. Hence, it can be concluded that there was no significant difference between COD removal efficiency (\%) and suspended solids removal efficiency $(\%)$ as $5 \%$ level. In PABFR, the removal efficiency COD and SS was 90 and $95 \%$ at 12-h HRT, and slightly decreased to 89 and $94 \%$ at 8-h HRT, and as the HRT decreased further to $4 \mathrm{~h}$, the efficiency lowered drastically to 64 and $83 \%$; this may be due to the inadequate contact between the biomass and the substrate. The biogas production in the case of 12,8 , and $4 \mathrm{~h}$ was $0.33,0.32$ and $0.22 \mathrm{~m}^{3} / \mathrm{kg}$ COD destroyed, respectively, as shown in Table 3 . In this context, an inadequate contact between biomass and substrate was meant to refer 4-h HRT, as in lower HRT, element of fluid passes out quickly compared to the higher HRT. However, it was observed that biogas production was almost the same at 8- and 12-h HRT. This might be because portion of influent COD is converted into gas-phase $\mathrm{CH}_{4}$ and liquidphase $\mathrm{CH}_{4}$ and remaining fraction is converted into biomass COD and effluent COD. In the present case, biogas production was meant to refer only in gas-phase $\mathrm{CH}_{4}$. At 12-h HRT, split up of influent COD as discussed above might differ as compared to 8 and 4-h HRT, keeping similar fraction of gas-phase $\mathrm{CH}_{4}$. This could be the possible reason for almost similar biogas production obtained at 12- and 8-h HRT. 
Fig. 4 COD concentration and removal efficiency in PABFR

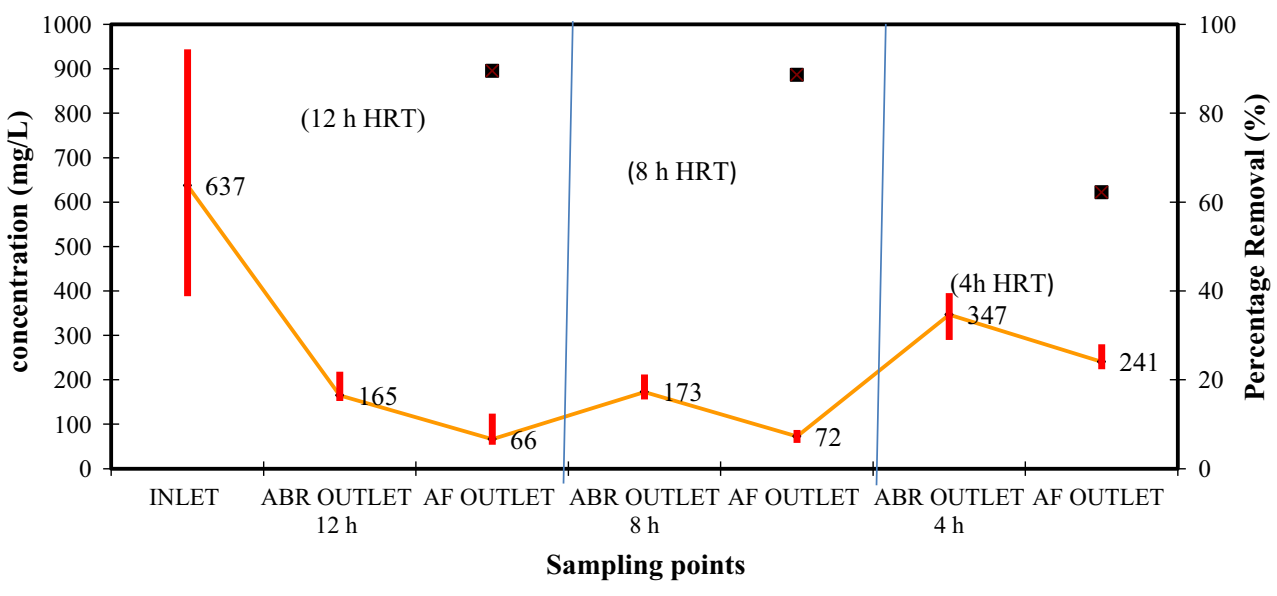

An important factor in wastewater treatment is the production of soluble microbial products (SMPs). These can be defined as compounds of microbial origin which results from substrate metabolism and biomass decay and have been found to account for the majority of soluble organic material in the effluent from biological treatment process (Leslie Grady et al. 1999). With low-strength feed (sewage/domestic wastewater), the contribution of SMP to effluent COD can be important and their production and degradation(less degree) might have occurred in compartmentalized structure of the anaerobic baffled cum filter.

In this study, the anaerobic baffled reactor and anaerobic filter are combined as one reactor. The anaerobic baffle chamber in the front part with three compartments played a major role in removing 50-60\% of the influent domestic wastewater concentration, and as the wastewater moves on to anaerobic filter in the rear part, the bacteria in the biofilm were involved in removing the remaining substrate concentration and SMPs which were formed.

The biomass inventory in AF is usually controlled by hydrodynamic conditions that develop in the media as a result of influent flow applied. The contribution of biofilm on filter media has been of several folds. Treatment occurs as a result of the suspended and fixed biomass retained by the media. As a result of degradation, gas is collected under bioreactor cover. With biofilm, a portion of incoming COD is converted into gas-phase methane, liquid-phase methane and biomass COD. Remaining portion is left unutilized that contributed to effluent COD as discussed above. In addition to above split up of organic load, by metabolic activity of bacteria, soluble organic matter in the effluent from a bioreactor is produced by microbial population as they degrade organic load (substrate) in the influent. SMPs are usually growth-associated which results directly from biomass growth and substrate utilization. As biomass growth proliferates in the media, it is quite obvious to have SMP. Since molecular weight of SMP is higher than that of influent organic matter, their degradation is expected to be higher degree in the compartmentalized structure of anaerobic baffled cum filter reactor.

Methane content in the biogas was 63-68\%, and the rest was assumed as carbon dioxide, hydrogen sulphide and others. Thus, the corresponding methane production was $0.231,0.22$ and $0.15 \mathrm{~m}^{3} / \mathrm{kg}$ COD destroyed. The other unaccounted methane which was produced was solubilized in the effluent and escaped from the collection. The biogas production decreases when the mixing and contact between the biomass and substrate decreases, resulting in a reduced mass transfer rate ultimately hampering the performance efficiency of the reactor. Rajakumar et al. (2011) observed an average methane content in biogas varied between 46 and $56 \%$ with methane yield of $0.24 \mathrm{~m}^{3} \mathrm{CH}_{4} / \mathrm{kg}$ COD destroyed, while treating slaughter house wastewater in upflow anaerobic filter.

\section{Conclusion}

In this study, the hydrodynamic and treatment performance of PABFR was studied. Though PABFR was a combined reactor (ABR followed by AF), the RTD studies were performed individually for both.

- Hydrodynamic study revealed that the front part of the PABFR, that is, in the ABR part, the dispersion was intermediate between $\mathrm{PF}$ and CSTR, and as the hydraulic flow increased, it became completely CSTR (with maximum back-mixing). Thus, the pollutant conversion rate was decreased, resulting in the destitute treatment efficiency. In the case of AF located in the rear part, the dispersion was completely PF (minimum back-mixing) under 8- and 12-h HRTs, and as the HRT 
was decreased to $4 \mathrm{~h}$, the reactor became intermediate between PF and CSTR.

- The dead space for both ABR and AF did not exceed $15 \%$, even under high flow conditions which was very low when compared to other high-rate reactor designs.

- The results obtained at various HRTs identified the HRTs of 12 and $8 \mathrm{~h}$ to be the most appropriate HRTs in terms of economic operation of the reactor, and at 12 and $8 \mathrm{~h}$, the reduction efficiencies of SS and COD were in the range of 90 and $95 \%$, respectively.

- Under PF condition, the incoming substrate remains in the reactor for one retention time, allowing maximum conversion; however, high substrate concentration resulting from lack of dispersion may inhibit bacterial activity; on the other hand, excessive dispersion may result in the short circuiting of substrates. An intermediate degree of mixing appears to be optimal for substrate conversion.

- This paper clearly demonstrates a qualitative relationship between hydrodynamic behaviour and treatment performance of PABFR, pointing that the hydraulic retention time is the key factor in the treatment of wastewater.

Acknowledgments The project was sponsored by University Grants Commission (UGC). The authors would like to thank the management of STP at the Anna University Campus for their cooperation throughout the study, and the authors extend their thanks to Ms. Anu Rachel Thomas and Ms. Sowmiya for their technical assistance during the study.

\section{References}

American Public Health and Association (APHA) (1998) Standard methods for the examination of water and wastewater, 19th edn. United Book Press, USA

Barber WP, Stuckey DC (1999) The use of anaerobic baffled reactor $(\mathrm{ABR})$ for wastewater treatment: a review. Water Res 33(7):1559-1578

Bodin H, Mietto A, Ehde PM, Persson J, Weisner S (2012) Tracer behaviour and analysis of hydraulics in experimental free water surface wetland. J Ecotechnol 49:201-211

Bodkhe SY (2009) A modified anaerobic baffled reactor for municipal wastewater treatment. J Environ Manag 90(8):2488-2493

Capela I, BiléM J, Silva F, Nadais H, Prates A, Arroja L (2009) Hydrodynamic behaviour of a full-scale anaerobic contact reactor using residence time distribution technique. J Chem Technol Biotechnol 84(5):716-724

Chen X, Zheng P, Guo Y, Mahmood Q, Tang C, Ding S (2010) Flow patterns of super-high-rate anaerobic bioreactor. Bioresour Technol 101(20):7731-7735

Feng H, Hu L, Shan D, Fang C, Dong S (2008) Effects of temperature and hydraulic residence time (HRT) on treatment of dilute wastewater in a carrier anaerobic baffled reactor. Biomed Environ Sci 21:460-466

Fogler HS (2006) Elements of chemical reaction engineering, 4th edn. Pearson Education, London
Gopala Krishna GVT, Kumar P, Kumar P (2008) Treatment of low strength complex wastewater using an anaerobic baffled reactor (ABR). Bioresour Technol 99(17):8193-8200

Grobicki A, Stuckey DC (1992) Hydrodynamic characteristics of the anaerobic baffled reactor. Water Res 26(3):371-378

Holland JF, Martin JF, Granata T, Bouchard V, Quigley M, Brown L (2004) Effects of wetland depth and flow rate on residence time distribution characteristics. Ecol Eng 23(3):189-203

Ji J, Zhe K, Xing Y, Zheng P (2012) Hydraulic characteristics and their effects on working performance of compartmentalized anaerobic reactor. Bioresour Technol 116:47-52

Ji Y-X, Xing B-S, Yang G-F, Ni W-M, Guo L-X, Jin R-C (2014) Performance and hydrodynamic features of a staged up-flow ANAMMOX sludge bed (SUASB) reactor. Chem Eng J 253:298-304

Jimenez B, Noyola A, Capdeville B (1988) Selected dye for residence time distribution evaluation in bioreactors. Biotechnol Tech 2(2):77-82

Kobayashi T, Li Y-Y (2011) Performance and characterization of a newly developed self-agitated anaerobic reactor with biological desulfurization. Bioresour Technol 102(10):5580-5588

Leslie Grady CP, Daigger GT, Lim HC (1999) Biological wastewater treatment, 2nd edn. Marcel Dekker, New York

Levenspiel O (1999) Chemical reaction engineering, 3rd edn. Wiley, New York

Lindmark J, Thorin E, Fdhila RB, Dahlquist E (2014) Effects of mixing on the result of anaerobic digestion: review. Renew Sustain Energy Rev 40:1030-1047

Liu X, Ren N, Wan C (2007) Hydrodynamic characteristics of a fourcompartment periodic anaerobic baffled reactor. J Environ Sci (China) 19(10):1159-1165

Mansouri Y, Zinatizadeh AA, Mohammadi P, Irandoust M, Akhbari A, Davoodi R (2012) Hydraulic characteristics analysis of an anaerobic rotatory biological contracto (AnRBC) using tracer experiments and response surface methodology (RSM). Korean J Chem Eng 28(7):891-902

Metcalf and Eddy (2003) Wastewater engineering: treatment, disposal, and reuse, 4th edn. McGraw-Hill, New York

Persson J, Somes NLG, Wong THF (1999) Hydraulics efficiency of wetlands and ponds. Water Sci Technol 40(3):291-300

Pritchard DW, Carpenter JH (1960) Measurements of turbulent diffusion in estuarine and inshore waters. Int Assoc Sci Hydrol Bull 5(4):37-50

Qi W-K, Hojo T, Li Y-Y (2013) Hydraulic characteristics simulation of an innovative self-agitation anaerobic baffled reactor (SAABR). Bioresour Technol 136:94-101

Rajakumar R, Meenambal T, RajeshBanu J, Yeom IT (2011) Treatment of poultry slaughterhouse wastewater in upflow anaerobic filter under low upflow velocity. Int $\mathrm{J}$ Environ Sci Technol 8(1):149-158

Ren TT, Mu Y, Yu HQ, Harada H, Li YY (2008) Dispersion analysis of an acidogenic UASB reactor. Chem Eng J 142:182-189

Sarathai Y, Koottatep T, Morel A (2010) Hydraulic characteristics of an anaerobic baffled reactor as onsite wastewater treatment system. J Environ Sci (China) 22(9):1319-1326

Smith CL, Elliot DJ, James A (1996) Mixing in upflow anaerobic filter and its influence on performance and scaleup. Water Res 30(2):3066-3076

Tembhurkar AR, Mhaisalkar VA (2006) Study of hydrodynamic behavior of a laboratory scale upflow anaerobic fixed film fixed bed reactor. J Environ Eng 48(2):75-80

Terashima M, Goel R, Komatsu K, Yasui H, Takahashi H, Li YY, Noike $T$ (2009) CFD simulation of mixing in anaerobic digesters. Bioresour Technol 100(7):2228-2233 
Thackston EL, Shields FD, Schroeder PR (1987) Residence time distribution of shallow basins. J Environ Eng ASCE 113(6):1319-1332

Tomlinson EJ, Chambers B (1979) The effect of longitudinal mixing on the settleability of activated sludge. Technical report TR 122, Stevenage, England
Tsai DDW, Ramaraj R, Chen PH (2012) A method of short-circuiting comparison. Water Resour Manag 26(9):2689-2702

Wolkersdorfer C (2011) Tracer test in a settling pond: the passive mine water treatment plant of the $1 \mathrm{~B}$ mine pool, Nova Scotia, Canada. Mine Water Environ. doi:10.1007/s10230-011-0147-3 